\title{
EL DISCURSO DE LA CRIMINALIDAD Y DEL PODER PUNITIVO: REPRESENTACIONES SOCIALES, PREVISIBILIDAD Y PRINCIPIO DE ECONOMÍA COGNITIVA*
}

\author{
JOSÉ ÁNGEL FERNÁNDEZ CRUZ**
}

RESUMEN: La inherente irracionalidad del derecho penal necesita de una especial justificación discursiva. La realidad no queda simplemente reflejada en los discursos, sino que estos poseen una «vida propia»: son en sí realidades sui generis. Asimismo, el creciente protagonismo del discurso político criminal a la hora de legitimar bienes jurídicos colectivos o macrosociales encuentra una de sus explicaciones en el hecho de que el discurso posee también una naturaleza supraindividual que, al menos en parte, están formados por representaciones sociales compartidas. Estas percepciones compartidas persiguen la reducción del miedo y la demanda de seguridad. La búsqueda de lo previsible y el principio de economía cognitiva son mecanismos (mentales) frecuentemente utilizados para reducir el miedo y demandar seguridad.

PALABRAS CLAVE: Análisis crítico del discurso - política criminal - representaciones sociales - bienes jurídicos macrosociales.

\section{THE DISCOURSE OF CRIMINALITY AND PUNITIVE POWER: SOCIAL REPRESENTATIONS, PREDICTIVENESS AND COGNITIVE ECONOMY PRINCIPLE}

ABSTRACT: the inherent irrationality of Criminal law requires a special discursive justification. Discourses do not only reflect the reality, but they possess «their own life». They are themselves realities sui generis. As well, the growing prominent role played by criminal justice discourse in order to legitimise public legally protected interests, as example public health in illicit drug trafficking, is because of the fact that discourse also has a public nature. This public nature is made up among others by social representations. These perceptions follow the reduction of fear and the

Fecha de recepción: 29 de marzo de 2012.

Fecha de aceptación: 17 de junio de 2013.

** Doctor en Derecho Penal, profesor de Derecho Penal de la Facultad de Ciencias Jurídicas y

Sociales, Universidad Austral (Chile). Correo electrónico: josefernandez@uach.cl 
need for security. Predictability and principle of cognitive economy are mental processes that create social representations, in other words, they reduce fear and to demand security.

KEY WORDS: Critical analisys discourse - criminal justice - social representations - public legally-protected interests

\section{I) INTRODUCCIÓN}

La noción de discurso, como otros conceptos afines (sociedad o cultura), es esencialmente difusa. En las ciencias y saberes sociales podemos encontrar numerosas perspectivas a la hora de abordar la comunicación humana, entre las que podemos destacar la retórica, la psicología social, la etnografía, la pragmática y el análisis del discurso. No obstante, a pesar de la ingente e inabarcable bibliografía que estudia cómo nos comunicamos los seres humanos, podemos mencionar tres enfoques científicos que nos aportan los vértices del discurso, donde cada uno de ellos se encuentra vinculado con los restantes. El primero, trata el discurso mismo, es decir, el análisis de las estructuras del texto y la conversación. El segundo, se concentra en la estructura social y cultural del discurso, como una práctica o interacción social que llevan a cabo los usuarios del lenguaje en situaciones o contextos sociales específicos. Aquí el discurso forma parte de relaciones sociales complejas, como, por ejemplo, la penalización de un hecho, donde los participantes negocian o acatan ciertas reglas y estrategias a la hora de participar en un evento comunicativo. Y el tercero, desde una concepción cognitiva, establece las relaciones entre contexto social y los eventos comunicativos. El discurso no posee un sentido intrínseco, sino que se lo otorgan los usuarios del lenguaje. Estos acuden a un evento comunicativo con una biografía personal y unas creencias compartidas que dan sentido tanto a la producción del discurso como a su recepción. Por tanto, desde esta última perspectiva, los discursos no son reflejo de la realidad social, sino construcciones (mentales) de cada individuo que dan sentido al texto y la conversación y a los propios hechos sociales que trata el discurso ${ }^{1}$.

En los estudios de inspiración filosófica, como es el caso del derecho penal, el término discurso suele utilizarse para mostrar los valores, estrategias e ideologías que contienen los textos u otras formas de creación de significado, pero no se suele prestar atención al análisis de lenguaje. Así, por ejemplo, cuando se utiliza el término «discurso penal neoliberal»se

VAN Dijk, Teun A. (2000) "El estudio del discurso", en El discurso como estructura y proceso. Estudios sobre el discurso, vol. I. Traducción de Elena Marengo. Barcelona: Gedisa. pp. 43-44. 
hace referencia a una serie de características, ideologías, fines, etc., pero sin examinar cómo las estructuras del habla o del texto contribuyen a este modelo político criminal. El discurso entendido de esta manera suele recibir el nombre de orden del discurso ${ }^{2}$.

Este estudio, debido a la formación jurídica de su autor, no va ser ajeno a esta concepción del discurso. No obstante, debemos ser conscientes de la necesidad de incorporar a las ciencias penales los estudios de campo sobre los textos y demás formas de creación de significado realizado por un conglomerado de disciplinas científicas, entre las que destacan el Análisis del Discurso y, en especial, el Análisis Crítico del Discurso.

El estudio del discurso sobre la criminalidad puede llevarse a cabo desde la distancia, intentando ser objetivos e imparciales como lo exigen las normas académicas dominantes. Pero el derecho penal supone desde sus consecuencias la manifestación más patente de la desigualdad social que conlleva casi inevitablemente a una actitud crítica hacia el poder punitivo. El discurso como práctica social está gobernado por una serie de reglas que, al igual que en el Derecho, pueden ser vulneradas, manipuladas o modificadas. Por esta razón, resulta necesario conocer cómo se producen estas prácticas y qué funciones cumplen tales transgresiones. Como conclusión y, de acuerdo con los analistas críticos del discurso, el discurso contiene cuatro características fundamentales: 1) el uso del lenguaje, 2) el contexto social donde se produce, 3) el proceso cognitivo entre ambos, y 4) la dominación y desigualdad que crean y reproducen respecto de los más desfavorecidos.

El presente estudio tendrá como objetivo señalar algunas características generales del discurso sobre la criminalidad y del poder punitivo que nos permitan entender su complejidad e importancia. Estamos solamente ante una primera aproximación de lo que podemos denominar el tercer pilar de la política criminal y, por esta razón, resulta necesario seguir profundizando en cómo las prácticas discursivas inciden en la creación, aplicación y ejecución de las normas penales. Para la consecución de este objetivo, en primer lugar, dedicaremos algunas páginas a la concepción del discurso como medio de dominación social; en segundo lugar, haremos una breve mención al Análisis Crítico del Discurso como referente teórico de este estudio; y finalmente señalaremos algunas de las principales características del discurso sobre la criminalidad y del poder punitivo.

2 VAN Dijk (2000) 22-23. El propio autor nos ilustra las diferentes teorías, ciencias y saberes que se vienen ocupando del discurso desde su surgimiento como estudios modernos del discurso en los años 60 del pasado siglo, entre los que destacan: la etnografía lingüística, el estructuralismo, la gramática del discurso, la sociolingüística y la pragmática, la etnometodología, la psicología cognitiva, social y discursiva y los estudios de la comunicación. 


\section{1) EL DisCURSO COMO DOMINACIÓN SOCIAL}

El pensamiento crítico ha puesto de manifiesto la importancia del discurso como un medio de dominación social ${ }^{3}$. El acceso a formas específicas de discurso, por ejemplo, en la política, los medios de comunicación o la ciencia, constituye en sí mismo un recurso de poder. El discurso-poder significa, por último, que aquellos grupos que controlan los discursos más influyentes tienen también más posibilidades de controlar las mentes y acciones de los otros ${ }^{4}$. Ahora bien, el poder no suele ejercerse en forma coactiva, sino de manera sutil y rutinaria. El uso más eficaz de poder se da cuando quienes lo tienen logran hacer a quienes no lo disfrutan que interpreten el mundo desde su punto de vista. El poder, en este caso, se ejerce a través del consentimiento, y por esta razón, el discurso constituye una de las principales formas de legitimación democrática.

Los analistas críticos del discurso denominan a esta especial forma de persuasión como el proceso de hegemonía (Gramsci, 1971). De acuerdo con este proceso, el habla y los textos cotidianos tienen un carácter político. Esto no significa que las personas hablen normalmente de temas políticos, sino que todo discurso tiene el potencial de estructurar relaciones de poder y subordinación ${ }^{5}$. Esta dominación discursiva se representa en las diferentes fases de incriminación penal, e incluso con una mayor intensidad, ya que el derecho penal constituye una de las manifestaciones más evidentes e intensas de nuestro sistema social discriminatorio. Si queremos comprender el fenómeno de la criminalidad y del poder punitivo no basta con acudir a la realidad fáctica o a los valores, principios y límites del derecho penal, sino que debemos tener presente la realidad discursiva. En caso contrario, no podremos comprender y analizar fenómenos como miedo al delito o el aumento de las tasas de victimización con independencia de las tasas de criminalidad registrada.

Para comprender con toda su amplitud un determinado modelo penal debemos tomar en consideración no solo lo que se ha criminalizado, sino también aquello que se ha excluido de la protección penal. Por tanto, desde una perspectiva discursiva, debemos diferenciar, en primer lugar, dos subgéneros discursivos: aquel que se ocupa de legitimar la inclusión de un nuevo delito o de mantener su estatus en el caso de que se discuta

\footnotetext{
3 Habermas, desde su concepción consensualista del discurso, no duda en afirmar que el «lenguaje es también un medio de dominación y una fuerza social», Habermas, Jürgen (1992) Conocimiento e interés. Madrid: Taurus, p. 259.

VAN Dijk (2000) 26.

Por todos, Mumby, Dennis K.; Clair, Robin P (2000) “El discurso en la organizaciones”, en El discurso como interacción social. Estudios del discurso: una introducción interdisciplinar, vol. II. Traducción de Gloria Vitale, p. 267.
} 
su expulsión del derecho penal; y aquel que se opone a su penalización o se muestra a favor de su expulsión del derecho penal.

Teniendo presente el entorno o contexto social ${ }^{6}$ y político de la República de Chile, el discurso del modelo penal de seguridad ciudadana se ocupa de legitimar las conductas que nuestro sistema social debe proteger penalmente, y el discurso de exclusión de las clases más poderosas de descartar ciertos conflictos sociales del poder punitivo. La fundamentación de esta clasificación tiene como presupuesto el principal paradigma de la criminología, y no es otro que los sistemas penales criminalizan y castigan efectivamente una serie de conductas cometidas por algunos ciudadanos con unas características especiales, y excluye otras cometidas por otros ciudadanos, también, con unas características especiales. El elemento común del citado modelo y discurso es su naturaleza discriminatoria que he denominado con anterioridad con el término del modelo penal liberal discriminatorio, como concepto aglutinador de nuestro sistema penal chileno ${ }^{7}$.

La imposición de un determinado discurso sobre la criminalidad tiene una vital importancia a la hora de legitimar la protección de un bien jurídico macrosocial. Ejemplos de esta situación los encontramos, precisamente, en los delitos contra la salud pública. En el caso del consumo y tráfico de drogas derivadas del cannabis, a pesar de que existen buenas razones éticas y sociales para su expulsión del derecho penal, o al menos, para una protección menos intensa, el discurso constituye su única o principal fuente legitimadora. En el caso de los delitos medioambientales, por el contrario, a pesar de que su protección penal se encuentra justificada por una consistente fundamentación ética y social, el discurso ejerce una fuerza deslegitimadora de tal intensidad que, o bien consigue excluir al derecho penal como medio de control social, o bien, convierten a los delitos medioambientales en una nueva manifestación del derecho penal simbólico (ilegítimo).

Desde la teoría del Estado, abogamos por un modelo penal de corte (liberal) socialdemócrata, es decir, un sistema penal que intente mitigar los efectos discriminatorios que el mismo produce. El Estado social y de-

6 Aquí, el término "contexto» es utilizado desde una perspectiva objetiva y no subjetiva como viene siendo utilizada por una parte importante de los analistas críticos del discurso. Véase una propuesta sociocognitiva del contexto en: VAN Dijk, Teun (2011) Sociedad y discurso: Cómo influyen los contextos sociales sobre el texto y la conversación. Barcelona: Gedisa.

7 Este término -que, en principio, puede pecar de tautológico- hace mención a los dos niveles de discriminación que se producen en este modelo penal. El primero, estructural que emana del propio Estado liberal y que, por tanto, no puede eliminarse, sino, a lo sumo, mitigarse. El segundo nivel hace mención a las discriminaciones punitivas que el propio sistema liberal está en condiciones de superar como, por ejemplo, las relativas al medio ambiente o a la protección de la salud pública. Véase, Fernández Cruz, José Ángel (2006) "El Nuevo Código Penal: una lucha por el discurso de la criminalidad”. Política Criminal, No 1, A5, pp. 5-8. Disponible en: http://www.politicacriminal.cl/n 01/pdf 01/a 5.pdf 
mocrático es aquella forma de Estado que partiendo del reconocimiento de que el modelo liberal genera desigualdades sociales y económicas y de su obligación de nivelarlas, asume jurídica y políticamente la obligación de intervenir en los procesos sociales. Esto conlleva la obligación de mitigar la discriminación criminal, no solo en el orden fáctico, sino también en el discursivo. Por tanto, en primer lugar, debemos desenmascarar los discursos discriminatorios en el orden penal y, en segundo, procurar, en la medida de lo posible, una situación ideal de diálogo que permita el acceso de discursos alternativos al debate político criminal.

\section{2) EL ANÁLISIS CRÍTICO DEL DISCURSO COMO REFERENTE TEÓRICO}

El presente estudio, en consonancia con lo anteriormente sugerido, tomará como referencia teórica el denominado Análisis Crítico del Discurso (en lo sucesivo ACD). En un estudio anterior, he desarrollado con mayor profundidad la relevancia del $\mathrm{ACD}$ en ámbito de las ciencias penales y, en especial, respecto de la criminología, poniendo de relieve que este tipo de análisis constituye una provechosa herramienta analítica para comprender la criminalidad y el poder punitivo ${ }^{8}$. No obstante, este artículo no pretende realizar un análisis crítico de textos y otras formas de creación de significado que ponga de relieve la naturaleza discriminatoria del derecho penal ${ }^{9}$, sino mencionar, a partir de los postulados del $\mathrm{ACD}$, algunas características generales que, a mi entender, concurren en los discursos sobre la criminalidad y del poder punitivo, especialmente, aquellos que ha desarrollado el ACD en el contexto general del procesos de dominación y exclusión en las sociedades contemporáneas. Para facilitar la compresión del presente estudio, mencionaré a continuación, sucintamente, sus principales contenidos, particularidades, objetivos y metodologías.

El ACD es un tipo de investigación analítica que estudia el modo en que el abuso del poder y la desigualdad social son practicados, reproducidos y, en menor medida, combatidos por los textos y el habla en un determinado contexto social y político ${ }^{10,11}$. A partir de su propio título,

8 Fernández Cruz, José Ángel. "El análisis crítico del discurso. Una nueva forma de aproximarse a la criminalidad y al poder punitivo". Revista de Derecho (Valparaíso), de próxima publicación.

$9 \quad$ En el artículo "El nuevo Código Penal: una lucha por el discurso político criminal", realicé un pequeño análisis de la prensa que abordó la contaminación acaecida en el Santuario de la Naturaleza (humedal sito en las proximidades de la ciudad de Valdivia en la XIV región de Chile. Fernández Cruz (2006) 17-30.

10 VAn Dijk (2000) 23

11 Su orientación crítica hacia el lenguaje y el discurso se inició con la «lingüística crítica» nacida (principalmente en el Reino Unido y Australia) hacia finales de los años setenta por autores como Fowler, Hodge, Kress y Trew, y Mey. VAN Dijк (2000) 23. 
podemos extraer sus principales notas características. El discurso es considerado como una práctica social que, a la vez, y valga la redundancia, está configurado por el propio contexto social ${ }^{12}$. El análisis radica en el estudio de las relaciones dialécticas entre la semiosis y otros elementos de las prácticas sociales ${ }^{13}$. Y lo crítico nos indica que su ámbito de análisis se centra en las relaciones discursivas entre los que más sufren y los que detentan el poder; se preocupa, por tanto, de las relaciones entre lenguaje y poder ${ }^{14}$. Por esta razón, sus análisis se centran en los discursos institucionales, políticos, de género y mediáticos que dan testimonio de la existencia de relaciones de dominación y conflicto ${ }^{15}$.

Los analistas críticos del discurso analizan el lenguaje desde una perspectiva funcional, a saber, ¿quién utiliza el lenguaje?, ¿cómo y cuándo lo utiliza? y ¿por qué lo hace? Esta naturaleza funcional del uso del lenguaje presupone también que este se realiza dentro de sucesos sociales más complejos, como por ejemplo, el proceso legislativo para penalizar una conducta. Por último, constituye, como hemos manifestado, una interacción social de conocimientos, emociones y creencias. Esta interacción presupone un proceso cognitivo tanto del hablante como del receptor.

El ACD pretende hacer visible las estructuras lingüísticas de poder que aparecen en los textos, como de otras formas de creación de significado (imágenes, lenguaje corporal, etc.) ${ }^{16}$. El poder no solo influye en los procesos donde los discursos se trasforman en acciones, sino también en la creación de otros discursos ${ }^{17}$. Además, existe un poder sobre el acceso a las formas de producción discursiva o, en otras palabras, el control de los medios donde se reproducen los discursos (medios de comunicación, universidades, centros religiosos, etc.) constituye un presupuesto necesario en la relaciones de dominación.

Como ciencia o saber social, además de su función descriptiva-que coincide con la esencia de la criminología- tiene una vocación de guía de la acción humana y, por tanto, en el ámbito de la criminalidad formaría parte de la política criminal. Desde su perspectiva crítica se entiende el discurso como un mecanismo de ilustración y emancipación. Para el ACD el lenguaje carece de poder propio y se obtiene por el uso que las personas hacen de él. De esta suerte, desde su dimensión prescriptiva,

\footnotetext{
12 Fairclough, Norman (2003) "El análisis crítico del discurso como método de investigación de las ciencias sociales”, en Métodos de análisis crítico del discurso. Barcelona: Gedisa, p. 172. Fairclough (2003) 179.

WodaK, Ruth (2003) "De qué trata el análisis crítico del discurso (ACD) - Resumen de su historia, sus conceptos fundamentales y sus desarrollos”, en Métodos de análisis crítico del discurso. Barcelona: Gedisa, p. 30.

15 WODAK (2003) 18.

16 WODAK (2003) 20.

17 Por todos, JäGER Siegfried (2008) "Entre las culturas: caminos fronterizos en el análisis del discurso", en Discurso y Sociedad, p. 507.
} 
propugna, en primer lugar, el desmantelamiento de aquellos discursos actualmente dominantes que actúan exacerbando los conflictos ligados a los otros (inmigrantes, criminales, etc.); y en segundo lugar, el desarrollo de una red de discursos alternativos, principalmente, en la política y en los medios de comunicación que anule o mitigue estas relaciones de dominación. De esta suerte, contamos en la actualidad las guías o pautas de comportamiento destinadas a evitar la utilización del lenguaje sexista ${ }^{18}$.

En este estudio, y de acuerdo con el ACD, vamos a utilizar el término «discurso» desde tres perspectivas o niveles. El primero, hace referencia a su concepción como práctica social que, como tal, posee unas características especiales respecto de otras experiencias sociales. El segundo, delimita las prácticas discursivas desde un concreto ámbito social, como por ejemplo, el discurso de género, sobre la inmigración y, en nuestro caso, el discurso de la criminalidad y del poder punitivo. Y el tercero, descubre y analiza en cada ámbito social la red de discursos específicos que establecen sus características generales y, en especial, dan contenido al conjunto de simbolismos o representaciones sociales que todo discurso posee como práctica social. Así, por ejemplo, el discurso sobre el consumo y tráfico de drogas contiene una red de discursos que construyen unas percepciones generales compartidas y que permiten establecer consensos y acciones, entre las que podemos destacar: el discurso causa-efecto entre drogas y crimen o el discurso sobre los graves dańos a la salud que producen las drogas, sin especificar el tipo de drogas, ni diferenciar entre consumo y abuso. Estas representaciones sociales compartidas han incidido en acciones concretas, como, por ejemplo, la última reforma del Reglamento de la Ley 20.000 sobre drogas que ha catalogado como droga dura la marihuana y demás derivados del cannabis.

Antes de comenzar con el desarrollo de este trabajo, debemos advertir que esta visión crítica no supone asumir en su totalidad el pensamiento de la ideología del dominante en el ámbito de las relaciones discursivas $^{19}$, es decir, entender que el derecho penal exclusivamente responde a los objetivos y fines de los más poderosos. Desde una perspectiva del realismo crítico, nunca está mal recordar que el derecho penal responde a una realidad social que la sufren, precisamente, las clases menos favorecidas. Tampoco debe tomarse este artículo como una adhesión incondicional al pensamiento posmodernista. Si bien el discurso constituye un

18 JäGER (2008) 522. En el ámbito legislativo podemos encontrar medidas preventivas que inciden en la configuración de los discursos. Así en el derecho penal español, el Capítulo II de la Ley Orgánica 1/2004, de 28 de diciembre, de Medidas de Protección Integral contra la Violencia de Género, establece varias medidas, como por ejemplo, la inclusión de un discurso que garantice la igualdad entre hombres y mujeres "desde la perspectiva de género», así como la formación discursiva de los profesionales de los medios de comunicación.

19 Yvonne, Jewkes (2011) Media \& Crime (Key Approaches to Criminology). 2a edición. Londres: Sage Publications, pp. 21-22. 
aspecto central a la hora de configurar el derecho penal, e incluso podríamos afirmar que es una de los ámbitos sociales donde posee una mayor relevancia, los discursos sobre la criminalidad por muy discriminatorios y manipuladores que puedan ser siempre poseen una conexión con la realidad fáctica empíricamente demostrable ${ }^{20}$ o reflejan cuestiones éticas o de principios. Como hemos manifestado en otras investigaciones, la legitimación del derecho penal, como cualquier medio de control social, responde en mayor o menor medida a consideraciones éticas, sociales y discursivas $^{21}$.

\section{II) Algunas nOtas generales SObRE EL DisCuRSO DE LA CRIMINALIDAD Y DEL PODER PUNITIVO}

A continuación, señalaremos algunas características generales del discurso sobre la criminalidad y del poder punitivo. Algunas de ellas son reflejo de las establecidas con carácter general por los analistas críticos del discurso, otras, por el contrario, constituyen propiedades específicas de los fenómenos de la criminalidad y del poder punitivo.

El presente epígrafe tomará como referencia sendos estudios específicos sobre el modelo penal de seguridad ciudadana y el discurso de exclusión de los más poderosos. El primero dedicado a la penalización del tráfico y consumo de las drogas, especialmente de las derivadas del cannabis ${ }^{22}$, y el segundo destinado a los procesos discursivos de exclusión de los delitos contra el medio ambiente ${ }^{23}$. Como es sabido, las figuras delictivas de ambos protegen la salud pública, es decir, bienes jurídicos macrosociales. Esta naturaleza supraindividual supone que carecen de la plasticidad de la mayoría de los delitos de naturaleza microsocial y la manera de complementar esta ausencia de facticidad o, en otras palabras, de compensar esta carencia de legitimidad, es, precisamente, a través del discurso.

20 Véase una visión crítica a la concepción antirrealista de criminología posmoderna en: Matthews, Roger A. (2010) "The construction of 'So What?' Criminology: A Realist Analysis". Crime, Law and Social Change, vol. 54, pp. 125-140.

21 Fernández Cruz, José Ángel (2009) “La legitimación ética de las leyes penales. Reflexiones desde la ética procedimental”. Revista de Derecho (Valdivia), vol. XXII, No 2; Fernández Cruz, José Ángel (2009) "La Legitimación social de las leyes penales. Límites y ámbito de aplicación”. Revista de Derecho (Valparaíso), vol. XXXIII, 2o Semestre.

22 Fernández Cruz, José Ángel (2006) “Tráfico de drogas: ética, realidad social y discurso”, en Derecho penal y criminología como fundamento de la politica criminal. Homenaje al profesor Alfonso Serrano Gómez, Bueno Arús, F.; Kury, H.; Rodríguez Ramos, L.; Zaffaroni, E. R. (directores), Madrid: Dykinson.

23 Fernández Cruz (2006) 1-30. 


\section{1) LA UBICUIDAD DEL DISCURSO POLÍTICO CRIMINAL}

El discurso sobre la criminalidad afecta transversalmente a la política-criminal, ya que no solo define los conflictos sociales que deben protegerse penalmente y legitima las funciones o fines de la pena ${ }^{24}$, sino que a la vez incide en todas las instituciones y diferentes etapas de criminalización, entre las que debemos destacar: los debates parlamentarios, la actuación de la policía, la aplicación del derecho penal por parte de lo operadores jurídicos, la elaboración de la dogmática penal y el cumplimento de las penas. Además, un determinado discurso respecto de algunos de estos aspectos puede afectar a otras instituciones o etapas de criminalización. Así por ejemplo, el discurso sobre la capacidad resocializadora de la pena no solo afecta directamente al sistema penitenciario, sino también, por ejemplo, a la manera en que los tribunales aplican las penas. Incluso, pueden concurrir al mismo tiempo discursos contradictorios sobre la criminalidad. Suele ocurrir en el denominado bienestarismo autoritario, donde se entremezclan discursos de protección de los menos favorecidos con discursos de tolerancia cero hacia la criminalidad.

A lo anterior, y desde la terminología usada por los analistas del discurso, podríamos afirmar que los discursos penales (político-criminales, criminológicos y dogmáticos) poseen un fuerte componente de interdiscursividad, es decir, la construcción de un texto, por ejemplo, una sentencia judicial, a partir de discursos político-criminales, criminológicos y dogmáticos. Esto supone que podemos encontrar en un mismo texto varios planos discursivos que, con independencia de la valoración positiva que supone per se la interdisciplinariedad, también aumentan las posibilidades de manipulación o dominación utilizando un plano discursivo para justificar un discurso o acción perteneciente a otro. Por ejemplo, en la fundamentación de una sentencia relativa al tráfico de drogas, se puede agravar la pena -dentro de los límites que impone el arbitrio judicial- en consideraciones preventivo generales (discurso político-criminal) como consecuencia del aumento de este tipo de criminalidad (discurso criminológico).

\section{2) EL PREDOMINIO DEL DISCURSO POLÍTICO-CRIMINAL}

Estamos ante una característica coyuntural del actual modelo penal liberal discriminatorio. Chile participa, activamente, de este nuevo fenómeno, donde el derecho penal ha asumido funciones que antes eran

24 A este respecto, Zaffaroni ha puesto de manifiesto cómo la doctrina penal ha tratado, a través de las teorías de la pena (absolutas y preventivas), legitimar el poder punitivo del Estado, mero acto de poder, semejante al de la guerra, que no admite una explicación racional. Véase, Zaffaroni, Eugenio (2002) Derecho penal. Parte General. Buenos Aires: Ediar, pp. 37-78. 
realizadas por otras formas de control social. A falta de mejores alternativas, el derecho penal ha asumido el papel de código moral y un creciente protagonismo en la progresiva juridificación de nuestra sociedad ${ }^{25}$. Este proceso no resulta extraño. Si tenemos presente el alto componente emotivo que envuelve al derecho penal, el crecimiento de los medios de comunicación y la competencia entre ellos, no resulta difícil concluir que el discurso de los políticos recurra al derecho penal.

Continuando con el ejemplo del tráfico y consumo de drogas ilícitas, el discurso político criminal se ha centrado en el debate sobre su despenalización o mayor rigor punitivo. En este discurso hemos caído todos aquellos que abogamos por su despenalización, a pesar de que muchos de nosotros tenemos la firme convicción de que el derecho penal resulta el instrumento menos idóneo para resolver este conflicto social.

Si aceptamos que el aumento o disminución del consumo de drogas no guarda una relación directa con una mayor intervención penal, la despenalización del tráfico y consumo de drogas tampoco tiene una relación directa con el aumento o disminución del consumo de drogas. En un país con un modelo liberalizador y con un sistema penal que exclusivamente castiga aquellas conductas más graves relacionadas con el tráfico de drogas, puede suceder que, en un momento determinado, aumente el consumo y el tráfico. Automáticamente el discurso político-criminal, inspirado en el modelo penal de seguridad ciudadana, afirmará con firmeza y solemnidad que su causa es precisamente la permisividad del sistema penal, pero todos sabemos que la problemática resulta mucho más compleja y que las tasas de consumo de drogas dependen más directamente de otros factores que de la propia penalización o despenalización. En fin, estamos ante otro ejemplo más de cómo el discurso hace posible que ante un fenómeno complejo, como es, sin duda, el consumo de drogas, se articule una respuesta simple: el derecho penal.

\section{3) EL CARÁCTER MULTIFACÉTICO DEL DISCURSO DE LA CRIMINALIDAD}

El discurso sobre la criminalidad opera en varios planos (ciencia, ética, dogmática, política, medios de comunicación, vida cotidiana, etc.). Los denominados planos discursivos repercuten unos con otros, guardan relación y se utilizan recíprocamente ${ }^{26}$. Sin duda, la política criminal como instrumento de control social necesariamente debe nutrirse de to-

25 Dítz Ripollés, José Luis (2003) La racionalidad del derecho penal. Madrid: Editorial Trotta, p. 14.

26 Por todos, JAGËr (2003) "Entre la teoría, el método y la política: la ubicación de los enfoques relacionados con el ACD. Discurso y conocimiento: aspectos teóricos y metodológicos de la crítica del discurso y del análisis de dispositivos”, en Métodos del discurso. Barcelona: Gedisa, p. 85. 
dos los planos discursivos posibles. Ahora bien, junto al predominio del modelo penal como medio de control social altamente formalizado, se viene constatando a la vez un evidente protagonismo de los medios de comunicación y de la vida cotidiana en las decisiones político-criminales, en especial, de la víctima en detrimento de los grupos de expertos. El crimen se ha convertido en noticia. Años atrás ocupaba un lugar marginal en los medios de comunicación, pero en la actualidad una gran parte de las portadas, estudios, editoriales y artículos de opinión de los periódicos versan sobre la criminalidad. Sin duda, resulta especialmente palpable en los medios audiovisuales: "una imagen de un malvado narcotraficante vale más que mil palabras». A esta relación entre crimen y medios de comunicación se ha unido el poder político, relación que se retroalimenta, en no pocas ocasiones, a espaldas de cualquier consideración ética o criminológica. La participación de los medios de comunicación en la configuración del discurso sobre la criminalidad constituye un ejemplo más que pone en evidencia su carácter falaz, su ausencia de neutralidad y su desprecio a la realidad social difundida por las estadísticas criminales.

El topoi, "puerta giratoria», constituye el ejemplo paradigmático de cómo los medios de comunicación y los partidos políticos han creado una realidad discursiva a espaldas de las estadísticas criminales. Lucía Dammert pone en evidencia el considerable aumento de población penitenciaria en Chile, a pesar de la puerta giratoria:

«En la primera década de este siglo, la población penal en Chile, constituida tanto por: Detenidos, Procesados (antiguo sistema penal), Imputados (nuevo sistema penal) y los Condenados privados de libertad, experimentó un incremento en términos absolutos en orden al 54\%. Cabe destacar que el aumento en la primera mitad de la década, alcanza apenas un $10 \%$, registrándose su mayor variación en la segunda mitad del lustro, con una subida de un 37,5\%. Conforme al Balance de la Fundación Paz Ciudadana 2010, la tasa de población penal en nuestro país es de 305 personas (cada 100.000 personas) y ocuparía el tercer lugar en América del Sur, tras Guayana Francesa y Surinam» ${ }^{27}$.

Ahora bien, la crítica a este proceso de popularización por parte de los medios de comunicación no supone negar o limitar el derecho a la libertad de expresión y comunicación, sino a la forma e intensidad con que tratan el fenómeno de la delincuencia. Además, nunca debemos olvidar el papel que los medios de comunicación juegan en aquellos crímenes que el Estado no está interesado en investigar. A lo anterior debemos recordar

27 Dammert, Lucía, “¿Por qué aumenta la población penal en Chile? Un estudio criminológico longitudinal”, Revista Ius et Praxis, de próxima publicación. 
que el crimen constituye un verdadero problema social y, por ende, necesitado de ser abordado por los medios de comunicación.

\section{4) LA ESPECIAL CAPACIDAD DISCRIMINATORIA DEL DISCURSO POLÍTICO-CRIMINAL}

La irracionalidad inherente del derecho penal necesita de una especial justificación discursiva o, en otras palabras, la discriminación discursiva se manifiesta con especial intensidad en el derecho penal. Veamos cómo el discurso político-criminal discrimina tomando como ejemplo al tratamiento jurídico penal del consumo y tráfico de drogas en Chile.

El discurso sobre las drogas supone, ante todo, una excepción al discurso general sobre el consumo. El discurso sobre el consumo se identificó durante gran parte de nuestra historia con el abuso y el derroche, con algo moral y humanamente injustificable. Pero desde Keynes, el consumo va a dejar de asociarse al abuso y va a adquirir una connotación económica positiva. El desarrollo económico en el contexto de los conflictos internos de clase en el Periodo de Entreguerras y posterior a la Segunda Guerra Mundial reorientaron las prioridades económicas hacia el consumo interno. Así, en la actualidad constituye el principio de la riqueza y la abundancia económica; no solo ha dejado de ser un exceso, sino una necesidad económica ${ }^{28}$. La contradicción discursiva resulta evidente y, a la vez, muestra una de las causas de los crasos resultados en la lucha contra las drogas: tenemos un discurso limitado a un determinado bien de consumo que, a la vez, se encuentra destinado a una población educada desde la niñez en cultura desmedida del consumo.

La capacidad discriminatoria del discurso político criminal afecta al ámbito de la protección de la salud en dos aspectos. El primero de ellos, excluye del discurso la droga que está causando mayores daños a la sociedad chilena. Si no se conociera la realidad social de este país y solo se tuviera conocimiento de la normativa y de lo expresado por el gobierno y los medios de comunicación, se llegaría a la conclusión de que el consumo de drogas ilícitas constituye el principal problema de salud pública, equiparable al acaecido en otros países. Nada más alejado de la realidad. El verdadero problema social relacionado con las drogas en Chile no son

28 Domingo Comas, Diego (2004) "Análisis global del consumo", en Consumo de control de drogas: reflexiones desde la ética. Madrid: Fundación de Ciencias de la Salud, Madrid, pp. 9-14. Los precedentes sobre la creencia, inédita en la historia de la humanidad, de la disolución de los límites y la posibilidad de un consumo generalizado, tiene mucho que ver el impacto del positivismo científico y la consideración deificada de la tecnología. El ecologismo, con posterioridad, ha puesto de manifiesto la necesidad de limitar el consumo indiscriminado. Domingo Comas (2004) 15 y 17. 
las ilegales, sino las legales y, en concreto, el alcohol ${ }^{29}$. El segundo aspecto pone en evidencia la irracional discriminación a la hora de tipificar penalmente conductas que pueden afectar a la salud pública. Así, debemos destacar la falta de una adecuada protección penal al medio ambiente o al consumidor, en contraposición a la establecida para el tráfico de drogas, aun cuando todas ellas en mayor o menor medida afectan al bien jurídico "salud pública», salvo con el pequeño matiz - por cierto, de corte liberal- en que este último suele concurrir el consentimiento válido de la "víctima». Los discursos de exclusión, como, por ejemplo, el discurso del desarrollo económico, han jugado un papel fundamental a la hora de excluir el medio ambiente o la salud de los trabajadores de una adecuada protección penal.

Manifestaciones de la capacidad discriminatoria podemos encontrarlas en el orden ético, normativo y criminológico. En el orden ético el discurso de tolerancia cero omite cualquier referencia a los principios de autonomía de la libertad y de justicia que llevarían a cuestionar las diferencias entre un vendedor de pisco y otro de marihuana; en el orden normativo, la actual legislación sobre drogas supone una clara excepción a la política criminal de protección a la salud pública; y en el orden criminológico, los estudios de campo realizados por los organismos oficiales omiten o relegan a un segundo plano cualquier referencia a las drogas legales o a las estadísticas sobre el delito de lavado de dinero procedentes del tráfico de drogas.

Los analistas críticos del discurso, como hemos mencionado, pretenden hacer visible las estructuras lingüísticas de poder que aparecen en los textos. Podemos señalar en este sentido los denominados «esquemas discursivos» que ponen de relieve cómo la sistematización o categorización de un texto puede subrayar o enfatizar una determinada información. Así, por ejemplo, el aumento del consumo de una determinada bebida alcohólica puede tener una influencia claramente opuesta si aparece en la sección de economía o de salud pública de un determinado medio de comunicación.

29 De acuerdo al último de estos informes (1998), 17 de cada 100 chilenos han consumido alguna vez en la vida, alguna de las tres drogas ilícitas de mayor uso en el país: marihuana (16.77\%), pasta base $(2.27 \%)$ y clorhidrato de cocaína $(4.02 \%)$. El consumo durante el último ańo de cualquiera de las tres principales drogas ilegales es de $5.3 \%$, fuertemente explicado por el consumo de marihuana (4.73\%). El consumo en el último mes fue de $2.23 \%$ (CONACE, 1999). Respecto de las drogas legales, "casi 13 de cada cien chilenos ha consumido tranquilizantes en el último ańo; $70.84 \%$ ha ingerido alcohol; y $47.09 \%$ ha fumado tabaco. En el último mes, 7 de cada 100 chilenos usó tranquilizantes; 52 bebieron alcohol y 41 fumaron tabaco" (CONACE, 1999, p. 4). Hopenhayn; Rementería; Sunkey (1999) Criterios básicos para una politica de prevención y control de drogas. Santiago: CEPAL, p. 34. 


\section{5) LA AUTONOMÍA DEL DISCURSO}

Una de las principales características del discurso sobre criminalidad y del poder punitivo radica -como venimos mencionando- en su autonomía respecto de la legitimación ética y el daño social de la conducta. En los discursos, la realidad no queda simplemente reflejada, sino que los discursos poseen una "vida propia» ${ }^{30}$ : son en sí realidades sui generis. Tampoco son medios pasivos de información que la realidad proporciona, ni incluso elementos menos materiales que la realidad «fáctica». Por consiguiente, el análisis del discurso no trata únicamente de las interpretaciones de algo que ya existe; y por ello no se ocupa únicamente de un análisis destinado a la asignación post festum de un significado, sino del análisis de la producción de la realidad que el propio discurso crea al ser transmitido por personas con una biografía y en concreto contexto social ${ }^{31}$.

Asimismo, el creciente protagonismo del discurso político criminal a la hora de legitimar bienes jurídicos colectivos o macrosociales encuentra su explicación en el hecho de que el discurso posee también una naturaleza supraindividual. Como manifiesta Jäger, "pese a que todo el mundo aporta su grano de arena a la producción del "tejido" discursivo, ningún individuo ni ningún grupo específico determina el discurso (...). Por regla general, los discursos han evolucionado y se han vuelto independientes como consecuencia de procesos históricos» ${ }^{32}$.

Los propios términos "droga» $\mathrm{y}$ «drogodependencia» vienen definidos en gran medida por el discurso social institucionalizado. Estos conceptos están cristalizados en la cultura, la historia, la norma y el castigo ${ }^{33}$ de tal manera que el discurso sobre las drogas ha conseguido convertirse en una percepción socialmente compartida, es decir, en un vínculo entre el sistema social y el sistema cognitivo individual, que tiene como finalidad la traducción, homogeneización y coordinación de los hechos y exigencias externas con las experiencias subjetivas ${ }^{34}$. En conclusión, el discurso resulta especialmente eficaz a la hora de configurar percepciones socialmente compartidas, que en el ámbito penal encuentran su mejor caldo de cultivo en la protección de bienes jurídicos macrosociales.

\footnotetext{
30 Incluso, un corriente del análisis crítico del discurso otorga una importancia tal al discurso que niega la existencia de una realidad social al margen del discurso: si el discurso cambia, el objeto no solo cambia, sino que se convierte en un objeto diferente. JAGËR (2003) 71.

Por todos, pp. 66-67.

JAGËR (2003) 67.

Por todos, Ruggiero, Vicenzo (2000) Crime and Markets. Nueva York: Oxford University Press, pp. 34-78.

34 Por todos, VAN Dijk, Teun A. (2003) "La multidisciplinariedad del análisis crítico del discurso: un alegato en favor de la diversidad", en Métodos de análisis crítico del discurso. Barcelona: Gedisa, p. 145 y ss.
} 
La autonomía del discurso también podemos apreciarla de manera especial en la fundamentación o ratio legis de las leyes penales. Continuando con el tráfico y consumo de drogas ilícitas, el mensaje de S. E. el Presidente de la República de la actual Ley sobre drogas, expresa:

«La [derogada] ley $\mathrm{N}^{\circ} 19.366$ es un instrumento jurídico que, por medio de los organismos del Estado, ha permitido desarrollar, dentro del ordenamiento jurídico, la investigación, a nivel nacional e internacional, para identificar, procesar y condenar a grupos criminales dedicados a la elaboración y tráfico ilícito de drogas, lavado de dinero y desvío de grandes cantidades de sustancias químicas para el desarrollo de esta actividad criminal».

Como podemos apreciar, el discurso sobre la criminalización de las drogas se ha centrado en la lucha contra las grandes organizaciones criminales, creando una realidad virtual, es decir, discursiva sobre la aplicación de la Ley de Drogas, pero, como es bien conocido por los operadores jurídicos, su efectiva aplicación ha recaído inevitablemente en los pequeños y medianos traficantes.

\section{6) El discurso político-CRiminal COMO REFlejo de laS REPRESENTACIONES SOCIALES}

El discurso simplifica la explicación y compresión de un determinado conflicto social. Un medio que lo facilita son los denominados macrotemas o representaciones sociales. La construcción de estas percepciones compartidas parte del presupuesto de que los usuarios de una lengua no son capaces de memorizar y manejar todos los detalles de un determinado problema social y, más aún, si es de la complejidad de la criminalidad y de los medios penales de control social. Para ello organizan mentalmente estos significados mediante macrotemas semánticos, representaciones sociales o topoi.

Las representaciones sociales constituyen uno de los principales objetos de investigación de la psicología cognitiva y, en concreto, de la denominada cognición social. La cognición social estudia el conocimiento que las personas poseen del mundo en el que habitan, hablan y actúan ${ }^{35}$. Existen dos corrientes principales. La primera, la más aceptada por los psicólogos de orientación cognitiva, hace referencia al proceso mental de comprensión e interpretación de la información acerca del mundo social, en especial, respecto de conceptos abstractos. Su interés está centrado en los mecanismos psicológicos que hacen posible que los individuos perci-

35 Condor, Susan; Antaki, Charles (2000) "Cognición social y discurso", en Discurso como estructura y proceso, vol. I. Traducción de Elizabeth Maiuolo. Barcelona: Gedisa, p. 484. 
ban de una manera más o menos similar las relaciones sociales. La otra corriente hace hincapié en la construcción social de nuestro conocimiento y de la naturaleza, también social, de los perceptores. En cuanto al discurso, las posiciones mentalistas se suelen ocupar de descubrir los sesgos mentales en la producción y comprensión del discurso que, una vez identificados, pueden ser corregidos o eliminados. En cambio, los que postulan que la cognición humana se construye fundamentalmente a través de procesos sociales, tienden a tratar el discurso como un recurso cultural o ideológico, poniendo especial atención en la construcción del discurso por parte de comunidades, etnias, organizaciones, naciones, etc.

Para la cognición social mentalista, los seres humanos operan como máquinas individuales de procesamiento de la información. Se considera que los procesos cognitivos son relativamente automáticos $\mathrm{y}$, a menudo, involuntarios. El discurso es una cuestión de entendimiento y, por tanto, intermediado por procesos mentales: la actividad mental precede y produce el discurso. Esto quiere decir que el discurso adquiere significado mediante cierta clase de vínculo identificable con las circunstancias sociales, culturales o políticas (contexto social). A partir de esta afirmación, la cognición social mentalista intenta explicar cómo entendemos el mundo que nos rodea a través de la organización que realizan los individuos en categorías, esquemas y modelos y cómo utilizan esta información mediatizada que brindan estas categorías a través de, por ejemplo, la inferencia social, la atribución de causas y las actitudes ${ }^{36}$.

La categorización, según los enfoques mentalistas de la cognición social, es un atributo básico en los procesos mentales. En el tema que nos ocupa, el mundo penal contiene uno de los conjuntos más complejos y desconcertantes de información y estímulos ante los cuales cada individuo debe responder. Por esta razón, con el fin de simplificar esta tarea de percibir y reaccionar ante esta complejidad, el discurso penal se encuentra plagado de categorías generales, a saber, de estructuras mentales que suelen actuar de manera más o menos consciente y más o menos automática para suministrarnos actitudes que guíen nuestros actos y discursos ${ }^{37}$. Los esquemas y modelos mentales son mecanismos que las personas construyen fundamentalmente para enfrentarse a las situaciones rutinarias. Un principio general en el proceso cognitivo postula que los individuos tienden a valorar los hechos concretos, situaciones o discursos de manera positiva si concuerda con el esquema o modelo mental que previamente poseen y, viceversa, lo que resulte inconsistente o alejado se valorará negativamente. Como puede apreciarse, la cognición social mentalista otorga una cierta valoración negativa, aunque inevitable, de las representaciones sociales. No obstante, para otros enfoques, especialmente aquellos que se

\footnotetext{
36 Condor/AntaKi (2000) 456-458.

37 Véase con carácter general: Condor/Antaki (2000) 458-460.
} 
vinculan a la retórica o a la sociología, ven la categorización como una actividad positiva ${ }^{38}$.

La inferencia social trata de describir cómo el entorno social afecta en los juicios que realizamos de las personas y hechos. Por ejemplo, una de las inferencias más conocidas es la tendencia de dejarse impresionar de manera inapropiada con ejemplos extremos y vívidos. Los estereotipos suelen construirse con inferencias sociales. Siguiendo a Halmiton, el estereotipo (percibido por la mayoría) de que un grupo de personas (clase o etnia) son ladrones, es victima de dos inferencias que hacen que este grupo y sus hechos sean inolvidables para el resto: el robo es un acto antisocial y, por tanto, inolvidable en sí mismo y el grupo es numéricamente menor que el conjunto de los ciudadanos y, por ende, también más memorable ${ }^{39}$.

Las actitudes es aquello que, ante una determinada situación, nos lleva a actuar de una forma concreta, específica y que normalmente esta manera de actuar es constante y permanente en el tiempo. Se forman a partir de las evaluaciones generales que las personas realizan sobre lo favorable o desfavorable que resultan los objetos y las personas de su entorno. Aunque las actitudes parten del presupuesto de que el hombre es un animal informado, evaluador, este no siempre es fiable al momento de convertir esas creencias y sentimientos en acciones consistentes y discursos. Por esta razón, existe un especial interés en la cognición social por los cambios de actitudes ${ }^{40}$. De acuerdo con Rodrigues, podemos distinguir tres componentes de las actitudes:

1. Componente cognoscitivo: para que exista una actitud, es necesario que exista también una representación cognoscitiva del objeto. Está formada por las percepciones y creencias hacia un objeto, así como por la información que tenemos sobre un objeto.

2. Componente afectivo: es el sentimiento en favor o en contra de un objeto social. Es el componente más característico de las actitudes. Aquí radica la diferencia principal con las representaciones sociales y las opiniones -que se caracterizan por su componente cognoscitivo.

3. Componente conductual: manifiesta la tendencia a reaccionar hacia los objetos de una determinada manera. Es el componente activo de la actitud $^{41}$.

La segunda corriente en el estudio de la cognición social entiende el conocimiento humano como un producto social bajo un régimen de pro-

\footnotetext{
CONDOR/AnTAKi (2000) 460.

Citado por Condor/Antaki (2000) p. 461. Véase la bibliografía citada.

CONDOR/AnTAKi (2000) 464.

Rodrigues, Aroldo (1981) Psicología Social. México: Trillas, 78-98.
} 
piedad compartida con el resto del grupo o comunidad. Esta perspectiva trata de diferenciarse del "individualismo» de los enfoques mentalistas ${ }^{42}$ en el sentido de que tratan al individuo como actor social antes que un mero observador desinteresado. De acuerdo con Condor/Antaki, existen tres grandes corrientes:

a) Los enfoques culturales que consideran al individuado como portador de una cultura particular o de un conjunto de ideologías compartidas. Incluso, las concepciones mentalistas admiten que nuestras percepciones o creencias no pueden explicarse completamente a través de los procesos individuales de información, sino que algunos aspectos de la percepción, como lo estereotipos, reflejan la sociedad o cultura en la que el individuo se socializót ${ }^{3}$. Los enfoques culturales de la cognición social explican la percepción social en términos de "cultura" o "sociedad» a la que los individuos pertenecen. Suelen otorgar una mayor importancia a la ideología -antes que a los fenómenos cognitivos- a la hora de explicar las creencias y percepciones de los individuos. También critican el supuesto automatismo y falta de conciencia en la categorización social, ya que los seres humanos, a pesar de recurrir con frecuencia a categorías sociales, son capaces también de los opuestos, a saber, de la "particularización».

b) Los enfoques grupales que estudian a los cognoscentes sociales como miembros de colectividades con intereses particulares compartidos. Esta perspectiva, a pesar de reconocer que parte de nuestro conocimiento social y de nuestro discurso es reflejo de una cultura o ideología, ponen énfasis en la importancia de pertenecer a grupos específicos para la cognición humana, la acción y el discurso. El centro de interés es la forma en la que el actor social habla y piensa como miembro de una identidad colectiva. Parte del presupuesto de que los sujetos tienden a internalizar las demandas e intereses de los grupos específicos con los cuales se identifican. El sesgo sistemático en la cognición social supone la tendencia a percibir el comportamiento del grupo de un modo más favorable.

c) Los enfoques interpersonales se concentran en los procesos de interacción e interdiscursividad como forma de construir conjuntamente la realidad social. Las otras dos perspectivas entienden al actor social como algo relativamente separado de otros actores sociales, como alguien que refleja una cultura o ideología o manifiesta las identidades del grupo al que pertenece. Esta co-

\footnotetext{
42 Condor/Antaki (2000) 465.

43 Condor/Antaki (2000) 467.
} 
rriente pone especial énfasis en los mecanismos de construcción de estas identidades e ideologías. Por esta razón, dan prioridad al discurso, como el principal instrumento de interacción social. El discurso es un emprendimiento público construido por muchas manos y sus efectos van más allá de las personas involucradas. Como hemos mencionado con anterioridad, los actores sociales implicados en el discurso sobre las drogas no usan exclusivamente sus experiencias y estrategias individuales a la hora de participar en un evento comunicativo, sino que se apoyan también en marcos colectivos de percepción, como por ejemplo, la percepción social de que el consumo de drogas produce necesariamente graves daños a la salud individual.

Dentro de una estrategia discursiva tan importante es la propia participación en determinado discurso como la previa imposición de una determinada representación social, puesto que esta definirá los límites del desarrollo del propio discurso y de las acciones a tomar. El macrotema droga-delincuencia supone en la actualidad que una importante parte del discurso sobre las drogas trate de justificar y cuantificar las relaciones entre su consumo y tráfico y la delincuencia. Otro macrotema, como hemos visto, es la relación causa-efecto entre consumo de drogas y graves daños en la salud. Pero sin duda, el macrotema por excelencia radica en delimitar el discurso sobre las drogas en las ilegales y, por tanto, excluir del ámbito discursivo las legales.

Existen numerosas estructuras semánticas a la hora de crear un macrotema, como las metáforas, eufemismos, redundancias, etc. Un importante medio para la creación de representaciones sociales son las catacresis o fracturas de imagen, que están cobrando especial relevancia en el discurso político criminal. Estas catacresis operan creando vínculos entre determinadas afirmaciones y las áreas de experiencia de los receptores del discurso, superando las posibles contradicciones y generando, a la vez, creencias y aceptaciones compartidas. Por ejemplo, cuando un medio de comunicación afirma que «una oleada de delincuencia pone en peligro el comercio de la ciudad», constituye una fractura de imagen, porque los símbolos «comercio» (que significa progreso) y «oleadas» (que señalan una amenaza proveniente del exterior) vinculan dos imágenes que sirven para crear una representación social o simbolismo colectivo ${ }^{44}$, que, posteriormente, contribuirá a una determinada actitud frente a la delincuencia.

44 JAGËR (2003) 65. 


\section{1) PREVISIBILIDAD Y PRINCIPIO DE ECONOMÍA COGNITIVA: LA CREACIÓN DE REPRESENTACIONES SOCIALES Y ESTEREOTIPOS}

El contexto como fuente y límite de los eventos discursivos está compuesto por una parte antropológica y por otra social. Entre las primeras tenemos las emociones, gran parte de las actitudes y la expresión gestual que, en mayor o menor medida, son universales. Entre las segundas, encontramos el razonamiento en todas sus posibles manifestaciones (utilitarismo, solidaridad, etc.). Aunque las percepciones compartidas son esencialmente construcciones sociales, estas poseen también un parte antropológica.

No tenemos un cerebro, sino tres fundidos en una sola estructura. Por orden de aparición tenemos: el reptiliano situado en el tallo encefálico, el límbico (mamíferos primitivos), que envuelve este, y el neocórtex (mamíferos superiores). El primero regula nuestras funciones vitales que se caracterizan por la repetición. Respecto a la conducta humana se le suele atribuir la concepción de la delimitación territorial y la resistencia a los cambios que experimentan la mayoría de los seres humanos. Estas conductas que compartimos con los reptiles fundamenta la idea de previsibilidad que resulta esencial en la comunicación (persuasiva) ${ }^{45}$.

El cerebro límbico agrega las emociones al comportamiento humano, entre la que destaca el miedo ante lo desconocido. Parece ser que ponemos en marcha la emoción antes que el razonamiento. Esto explica que la criminalidad y su respuesta social se afronten más con las emociones que con el razonamiento. Como manifestó Freud en el Malestar de la cultura, «la sociedad se ha visto obligada a imponer normas externas destinadas a contener la desbordante marea de los excesos emocionales que brotan del interior del individuo» ${ }^{46}$.

Hemos heredado unos mecanismos de estímulo y respuesta, unas percepciones, unos modelos de conducta que nos unen, y que son empleados constantemente en la comunicación, y en especial en la comunicación persuasiva, como la publicidad y la política. Gran parte de las reacciones del comportamiento humano, como consecuencia de nuestro cerebro reptiliano y límbico, es decir, universales, persiguen fundamentalmente lo conocido y la reducción del miedo. La reducción del miedo es la que mueve una respuesta innata de nuestra especie: la búsqueda de seguridad ${ }^{47}$.

La previsibilidad elimina la incertidumbre y el miedo. Lo que no es familiar es hostil por desconocido; por esta razón, por ejemplo, una política criminal alternativa suele enfrentarse con una actitud de rechazo. El discurso político-criminal se ve atrapado, de esta manera, por la tendencia

\footnotetext{
45 Santiago Cuervos, Javier (2005) Principios de la comunicación persuasiva, en Cuadernos de la Lengua Española, N 86, pp. 17 y 18.

46 Citado por Santiago Cuervos (2005) 19.

47 Santiago Cuervos (2005) 26.
} 
humana de permanecer en el mundo conocido. El actual derecho penal fundamentado en la prisión supone una respuesta al miedo, una respuesta familiar que, además, se capta con un mínimo gasto de energía cognitiva.

El principio de economía cognitiva pone en evidencia que solemos optar por el pensamiento que menor coste de procesamiento exija y, por tanto, tiende a introducir toda la información dentro del mundo de lo previsible ${ }^{48}$. Por ejemplo, el principio de presunción de inocencia es una norma social que pretende evitar el pensamiento de que todo acusado es culpable, es decir, una respuesta al miedo al menor coste posible.

La sustitución de la realidad social por un mundo alternativo fracturado por los medios de comunicación cumple la función, entre otras, de que nuestras relaciones sociales funcionen de manera previsible. Lo que los medios no cuentan, sencillamente, no existe, porque la mayor parte del conocimiento sobre la realidad que poseen las personas proviene de la selección temática realizada por dichos medios que, a la vez, tienden también a aplicar el principio de economía cognitiva. Del mismo modo, el voto cautivo resulta especialmente permeable al discurso (político criminal) de su partido político o grupos de presión, etc.

Así, la creación de representaciones sociales, estereotipos y prejuicios son manifestaciones del principio de economía cognitiva que en las mayorías de las ocasiones buscan eliminar la incertidumbre y el miedo. Resumiendo, los discursos penales se encuentran especialmente afectados por nuestro cerebro reptiliano y límbico, es decir, persiguen la reducción del miedo y la búsqueda de seguridad. La búsqueda de lo previsible y el principio de economía cognitiva son mecanismos (mentales) que con frecuencia son utilizados, tanto por los receptores del discurso como sus creadores, para reducir el miedo y demandar seguridad.

\section{A MODO DE CONCLUSIÓN}

En este estudio he pretendido llamar la atención sobre la importancia del discurso en el derecho penal como medio de justificación y creación de realidades virtuales (bienes jurídicos protegidos). También, he querido ir más allá de las categorizaciones y adjetivaciones generales sobre el discurso sobre la criminalidad y del poder punitivo, poniendo especial énfasis en los aspectos sociocognitivos del discurso que tratan de explicar por qué el mundo penal constituye un atractivo campo de cultivo para la creación de percepciones y actitudes socialmente compartidas. 


\section{BIBLIOGRAFÍA}

- Condor, Susan y Antaki, Charles (2000) "Cognición social y discurso", en Discurso como estructura y proceso, vol. I. Traducción de Elizabeth Maiuolo. Barcelona: Gedisa.

- Dammert, Lucía, “¿Por qué aumenta la población penal en Chile? Un estudio criminológico longitudinal”. Revista Ius et Praxis, de próxima publicación.

- Díez Ripollés, José Luis (2003) La racionalidad del derecho penal. Madrid: Editorial Trotta.

- Domingo Comas, Diego (2004) "Análisis global del consumo", en Consumo de control de drogas: reflexiones desde la ética. Madrid: Fundación de Ciencias de la Salud, Madrid.

- Fairclough, Norman (2003) "El análisis crítico del discurso como método de investigación de las ciencias sociales", en Métodos de análisis crítico del discurso. Barcelona: Gedisa.

- Fernández Cruz, José Ángel, "El análisis crítico del discurso. Una nueva forma de aproximarse a la criminalidad y al poder punitivo". Revista de Derecho (Valparaíso), de próxima publicación.

- Fernández Cruz, José Ángel (2006) "El Nuevo Código Penal: una lucha por el discurso de la criminalidad". Política Criminal, No 1, A5, p. 5-8. Disponible en: http://www.politicacriminal.cl/n 01/ pdf 01/a 5.pdf

- Fernández Cruz, José Ángel (2006) "Tráfico de drogas: ética, realidad social y discurso", en Derecho penal y criminología como fundamento de la politica criminal. Homenaje al profesor Alfonso Serrano Gómez, Bueno Arús, F. - Kury, H. - Rodríguez Ramos, L. Zaffaroni, E. R. (dirs.), Madrid: Dykinson, 2006.

- Habermas, Jürgen (1992) Conocimiento e interés. Madrid: Taurus.

- Hopenhayn/Rementería/Sunkey (1999) Criterios básicos para una politica de prevención y control de drogas. Santiago: CEPAL.

- JäGER, Siegfried (2008) "Entre las culturas: caminos fronterizos en el análisis del discurso", en Discurso y Sociedad, 2 (3).

- JAGËr, Siegfried (2003) "Entre la teoría, el método y la política: la ubicación de los enfoques relacionados con el ACD. Discurso y conocimiento: aspectos teóricos y metodológicos de la crítica del discurso y del análisis de dispositivos”, en Métodos del discurso, Madrid: Gedisa.

- Matthews, Roger A. (2010) “The construction of 'So What?' criminology: a realist analysis", en Crime, Law and Social Change, vol. 54 (2).

- Mumby, Dennis K; Clair, Robin P. (2000) "El discurso en la organizaciones", en El discurso como interacción social. Estudios del 
discurso: una introducción interdisciplinar, vol. II. Traducción de Gloria Vitale.

- Rodrigues, Aroldo (1981) Psicología Social. México: Trillas.

- Ruggiero, Vicenzo (2000) Crime and Markets. Nueva York: Oxford University Press.

- Santiago Cuervos, Javier (2005) "Principios de la comunicación persuasiva”, en Cuadernos de la Lengua Española, No 86.

- Van Dijk, Teun A. (2003) "La multidisciplinariedad del análisis crítico del discurso: un alegato en favor de la diversidad", en Métodos de análisis crítico del discurso, Barcelona: Gedisa.

- Van Dijk, Teun A. (1999) "El análisis crítico del discurso", en Anthropos, $\mathrm{N}^{\circ} 186$, septiembre-octubre.

- Van Dijk, Teun A. (2000) "El estudio del discurso", en El discurso como estructura y proceso. Estudios sobre el discurso, vol. I. Traducción de Elena Marengo. Barcelona: Gedisa.

- Van Dijk, Teun A. (2011) Sociedad y discurso: cómo influyen los contextos sociales sobre el texto y la conversación. Barcelona: Gedisa.

- Wodak, Ruth (2003) "De qué trata el análisis crítico del discurso (ACD) - Resumen de su historia, sus conceptos fundamentales y sus desarrollos", en Métodos de análisis crítico del discurso. Barcelona: Gedisa.

- Yvonne, Jewkes (2011) Media \& Crime (Key Approaches to Criminology). Londres: Sage Publications.

- Zaffaroni, Eugenio (2002) Derecho penal. Parte General. Buenos Aires: Ediar. 